\title{
Evidence-Based Practice of Critical Care
}

\author{
Clifford S. Deutschman, Patrick J. Neligan. Saunders Elsevier, \\ 2010, 718 pages, ISBN 978-1-4160-5476-4
}

\author{
Mypinder S. Sekhon, MD • Donald E. G. Griesdale, MD
}

Published online: 24 November 2010

(C) Canadian Anesthesiologists' Society 2010

This book, the first in its series, addresses the need for a text that incorporates clinical evidence within the practice of critical care. It is authored by international experts in various disciplines of critical care medicine and encompasses all of the core topics in critical care medicine.

The book is categorized into sections based on individual organ systems, and within each section, there are succinct chapters that aim to answer key questions in the respective field. The key question may be general: "How should acid-base disorders be diagnosed and managed?" or more specific: "Should vasopressin be used in septic shock?" The information within each chapter flows elegantly from describing basic pathophysiology to presenting examples of both human and animal studies to responding to key questions and controversies in critical care. Current and original data from landmark studies are presented and interpreted for the reader. For example, the chapter examining the role of glycemic control in the intensive care unit includes a discussion regarding the landmark study, NICE-SUGAR, published in March 2009. Each chapter concludes with a point form summary of the salient points of the authors' recommendations. Furthermore, in several chapters, novel therapies are identified that may potentially become available, offering the reader an appreciation of the outlook for critical care medicine.

If readers are willing to provide some personal information, they can gain online access and search capabilities for the entire text by registering their books online at the expert consult website using a unique code provided at the front of the book.

Overall, this comprehensive and well written text is long overdue, and given the breadth of knowledge this book encompasses, it will appeal to critical care trainees and seasoned intensive care physicians alike. In addition, given its concise well organized chapters involving important critical care topics, this book will also appeal to physicians who care for critically ill patients on a less frequent basis. In summary, this text applies evidence-based medicine to the practice of critical care by linking the underlying pathophysiology with the appropriate diagnostic and therapeutic reasoning in a concise, logical, and intelligible manner.

M. S. Sekhon, MD - D. E. G. Griesdale, MD ( $₫)$

University of British Columbia, Vancouver, BC, Canada

e-mail: dgriesdale@ post.harvard.edu 